\title{
Separation of Titanium, Tungsten, Molybdenum, and Niobium by Anion Exchange
}

\author{
John L. Hague, Eric D. Brown, and Harry A. Bright
}

\begin{abstract}
The results of a systematic study of the elution behavior of titanium, tungsten, molybdenum, and niobium in various hydrochloric-hydroflouric acid media are given. These data demonstrate the behavior of the anion complexes of these elements on an anion-exchange resin column. The possibility of several interesting quantitative separations is evident, and experiments are described that demonstrate that these elements can be separated from each other.
\end{abstract}

\section{Introduction}

One of the more difficult problems of analytical chemistry is the separation of titanium, niobium, and tantalum. Existing methods $[1,2,3,5,6]^{1}$ for the separation of niobium and tantalum are not entirely satisfactory in the presence of titanium, and such methods are further complicated by additional separations when molybdenum and tungsten are present.

Kraus and Moore [4] have shown that niobium and tantalum can be separated as mixed chloro-fluoro anion complexes by use of an anion exchange resin in a hydrochloric-hydrofluoric acid medium. The results of a systematic study of the elution behavior of titanium, tungsten, molybdenum, and niobium in some hydrochloric-hydrofluoric acid media are presented here, as well as a demonstration of the separation of these elements from each other.

\section{Experimental Method}

\subsection{Preparation of Column}

The column used in these experiments was prepared from a 12-in. length of polystyrene tubing with a $7 / 8$-in. inside diameter. The bottom of the tube is closed by a waxed No. 5 rubber stopper with a $3 / 16$-in. hole. A 6 -in. length of polystyrene tubing with a $3 / 16$-in. outside diameter $(1 / 16$-in. bore) is inserted into the hole, flush with the upper surface of the stopper. Another 6-in. length of this tubing is attached to the smaller tube with a 2 -in. length of Tygon $\mathrm{R}$ tubing, and the flow controlled by a pinchcock on the Tygon tubing. The bottom of the large tube is covered with a $1 / 4^{-}$to $3 / 8$-in. layer of acidresistant vinyl chloride plastic "wool". The column is filled with prepared ${ }^{2} 200$ - to 400 -mesh Dowex-1 resin, of 8- to 10-percent crosslinkage, to obtain a settled column of the resin 8 in. high. A measure of the liquid capacity of the column of resin is determined by washing with neutral ammonium chloride (150 g/liter, $\mathrm{pH} 6)$ until the resin darkens, and then

Figures in brackets indicate the literature references at the end of this paper. 2 The finest and coarsest materials are removed from the main portion of the resin by settling in diluted hydrochloric acid $(1+19)$, and several cycles of successively decanting the fine and main portions of the resin from the coarse fraction. determining the volume of diluted hydrochloric acid $(1+3)$ required to lighten the color of the resin. The volume so determined was approximately $35 \mathrm{ml}$.

\subsection{Elution Procedure}

Acid mixtures to cover the range of 5 to 20 percent by volume of concentrated hydrofluoric acid $(48 \%)$ and 10 to 60 percent by volume of concentrated hydrochloric acid $(36 \%)$ were used. To expedite the work, the elements were run in pairs, molybdenum and titanium constituting one pair, and tungsten and niobium the other.

As an example of the procedure used, approximately $20 \mathrm{mg}$ of high-purity molybdic oxide and 20 $\mathrm{mg}$ of high-purity titanium dioxide were transferred to a platinum crucible and fused with $0.5 \mathrm{~g}$ of potassium bisulfate. The fusion was dissolved in $50 \mathrm{ml}$ of a mixture of 1 volume of hydrofluoric acid, 2 volumes of hydrochloric acid, and 17 volumes of water (designated 5-percent hydrofluoric-10-percent hydrochloric acid). The prepared column was washed with $50 \mathrm{ml}$ of the same hydrofluoric-hydrochloric acid mixture, and the eluate discarded. The solution of the fusion was transferred to the resin, the first $25 \mathrm{ml}$ of eluate being discarded. Elution of the resin was then continued with the hydrofluorichydrochloric acid solution, 50-ml fractions being collected in polystyrene graduates for analysis. Suitable portions (usually $10 \mathrm{ml}$ ) taken from each $50-\mathrm{ml}$ fraction as the elution procedure was continued, were examined for titanium and molybdenum. Fluoride was eliminated from these portions by evaporation (usually three times) with sulfuric acid and hydrogen peroxide. Molybdenum was determined by the thiocyanate photometric method and titanium by the peroxide photometric method [2].

Elution was continued until examination of the fractions showed that the titanium and molybdenum were removed from the column. The amount of each element in each fraction examined was then calculated to a percentage of the total amount of each element eluted, and the accumulated percentages were plotted against volume of eluate. The procedure was then repeated with a solution of a fusion of tungsten and niobium oxides, the tungsten being determined by the hydroquinone photometric procedure and niobium by the peroxide photometric procedure. 


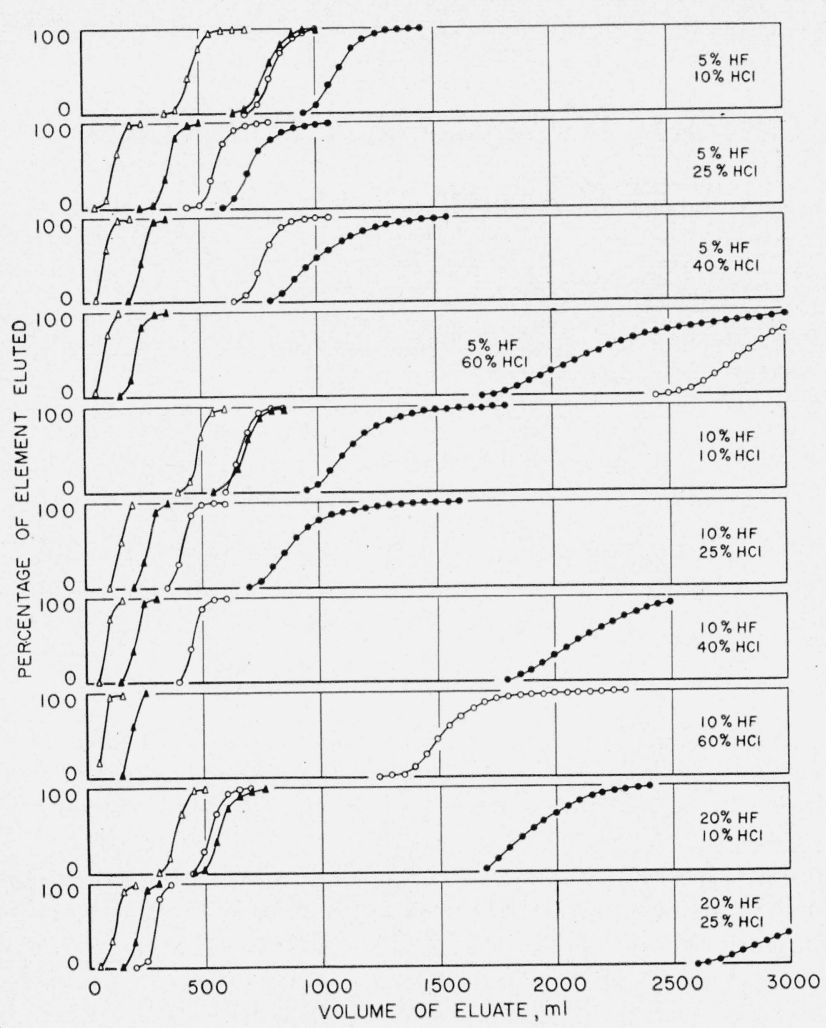

Frgure 1. Elution behavior of titanium, tungsten, molybdenum, and niobium.

$\triangle$, Titanium; $\mathbf{\Delta}$, tungsten; $\bigcirc$, molybdenum; $\bullet$, niobium.

\section{Results and Discussion}

The results of a series of experiments conducted as described above in various acid mixtures are presented in figure 1, except for niobium in 60-percent hydrochloric-10-percent hydrofluoric acid medium, in which niobium did not appear until more than 4 liters of eluate had been collected.

These curves demonstrate the possibility of several interesting quantitative separations. Titanium and niobium are easily separable under a wide variety of acid conditions, and as titanium is the first of the pair removed, even major quantities of titanium should offer few difficulties. Molybdenum and tungsten are also easily separable under several conditions; in fact, titanium and tungsten are the only pair of the group of elements considered here for which some latitude in separation does not exist.

To demonstrate that the separations can be made without the usual "loss of individuality" [5], several possible separation schemes were tried, and three of these are presented in figure 2 . Figures $2 \mathrm{a}$, and $2 \mathrm{~b}$, show the results of experiments involving 10 to $20 \mathrm{mg}$ of each element. A trial of procedure 2,b, indicated it does not work well in handling decigram quantities of these elements. The extra solutions at the beginning of experiment 2 ,b, were designed to remove iron and cobalt, which are absorbed even in fluoride solution in the presence of high chloride-ion concentration, and to provide for the elimination of the alkali bisulfate used for fusion of the oxides.

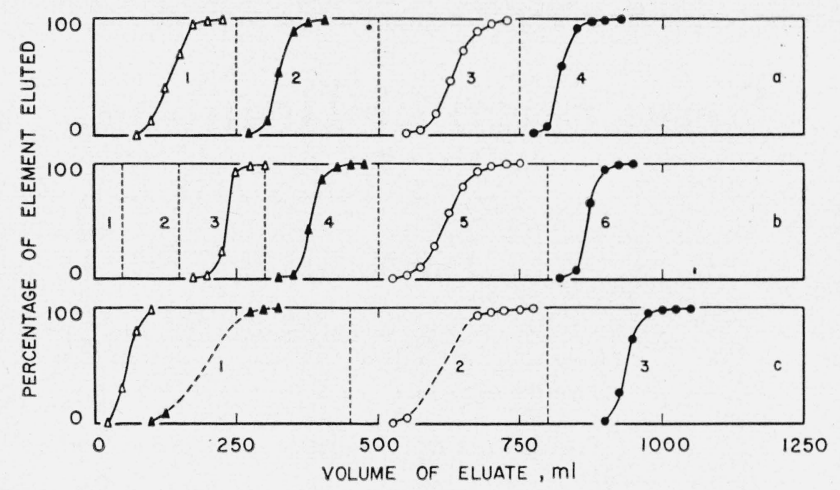

FIgure 2. Separation of titanium, tungsten, molybdenum, and niobium.

a. Fraction 1: $250 \mathrm{ml}$ of $25 \% \mathrm{HCl}-5 \% \mathrm{HF}$; fraction 2: $250 \mathrm{ml}$ of $40 \% \mathrm{HCl}-5 \% \mathrm{HF}$ fraction 3: $250 \mathrm{ml}$ of $40 \% \mathrm{HCl}-10 \% \mathrm{HF}$; fraction $4: 250 \mathrm{ml}$ of $14 \% \mathrm{NH}_{4} \mathrm{Cl}-4 \%$ HF.

b. Fraction 1: $50 \mathrm{ml}$ of $10 \% \mathrm{HCl}-20 \% \mathrm{HF}$; fraction 2: $100 \mathrm{ml}$ of $10 \% \mathrm{HCl}-5 \% \mathrm{HF}$; fraction 3: $150 \mathrm{ml}$ of $25 \% \mathrm{HCl}-5 \% \mathrm{HF}$; fraction $4: 200 \mathrm{ml}$ of $40 \% \mathrm{HCl}-5 \% \mathrm{H} \mathrm{F}$; fraction 5: $300 \mathrm{ml}$ of $40 \% \mathrm{HCl}-10 \% \mathrm{HF}$; fraction $6: 250 \mathrm{ml}$ of $14 \% \mathrm{NH}_{4} \mathrm{Cl}-4 \%$

c. Fraction 1: $450 \mathrm{ml}$ of $50 \% \mathrm{HCl}-10 \% \mathrm{HF}$; fraction 2: $350 \mathrm{ml}$ of $25 \% \mathrm{HCl}-20 \%$ $\mathrm{HF}$; fraction 3: $350 \mathrm{ml}$ of $14 \% \mathrm{NH}_{4} \mathrm{Cl}-4 \% \mathrm{HF}$ $\triangle$, Titanium; $\boldsymbol{\Delta}$, tungsten; $\bigcirc$, molybdenum;, niobium.

Figure 2,c, presents the separation of an oxide mixture obtained by suitable concentration from a 5-g sample of a high-temperature alloy and involves approximately $200-\mathrm{mg}$ amounts each of molybdenum, tungsten, and niobium, with residual amounts of titanium and tantalum. It may be seen that the separations are good even with these larger quantities. Details of the niobium-tantalum separation have been omitted, as such data are already available [4].

Quantitative experiments are well advanced, and detailed procedures for the separation and determination of the components of several mixtures of commercial interest are being investigated.

\section{Summary}

The elution characteristics of titanium, tungsten, molybdenum, and niobium in hydrochloric-hydrofluoric acid mixtures on a Dowex-1 resin column differ sufficiently to indicate the possible separation of these elements from each other. Experiments are described that demonstrate the quantitative separation of these elements without the usual loss of individuality.

\section{References}

[1] F. H. Burstall and A. F. Williams, Analyst 7\%, 983 (1952)

[2] W. F. Hillebrand, G. E. F. Lundell, H. A. Bright, and J. I. Hoffman, Applied inorganic analysis, $2 \mathrm{~d}$ ed. (John Wiley \& Sons, Inc., New York, N. Y., 1953).

[3] C. F. Hiskey, L. Newman, and R. H. Atkinson, Anal. Chem. 24, 1988 (1952)

[4] K. A. Kraus and G. E. Moore, J. Am. Chem. Soc. 73, 2900 (1951).

[5] W. R. Schoeller, The analytical chemistry of tantalum and niobium (Chapman \& Hall, Ltd., London, 1937).

[6] A. F. Williams, J. Chem. Soc., p. 3155 (London, 1952).

Washington, July 19, 1954. 